\title{
PERFIL METABÓLICO DE CORDEIROS SANTA INÊS TERMINADOS EM CONFINAMENTO COM MANEJO ALIMENTAR RESTRITIVO E $A D$ LIBITUM
}

\section{METABOLIC PROFILE OF SANTA INES LAMBS FINISHED IN FEEDLOT WITH FEEDING RESTRICTION AND AD LIBITUM}

\author{
Keli Daiane Cristina Libardi ${ }^{*}$ \\ Patricia Barcellos Costa ${ }^{1}$ \\ Ana Alix Mendes de Almeida Oliveira ${ }^{1}$ \\ Cristiani Cavilhão ${ }^{1}$ \\ Paula Regina Hermes ${ }^{1}$ \\ João Ricardo Pompermaier Ramella ${ }^{1}$ \\ ${ }^{1}$ Universidade Estadual do Oeste do Paraná, Marechal Candido Rondon, PR, Brasil. \\ “Autora para correspondência - keli_libardi@yahoo.com.br
}

\section{Resumo}

Objetivou-se avaliar o perfil metabólico de 24 ovinos Santa Inês, machos, com peso vivo médio inicial de $20 \pm 1,25 \mathrm{~kg}$, submetidos à restrição alimentar seguida de realimentação em confinamento, distribuídos em quatro tratamentos com 0, 20, 40 ou 60\% de restrição alimentar. Dois ensaios foram desenvolvidos, um referente à restrição e outro à realimentação. Para tanto, foi utilizado delineamento experimental inteiramente ao acaso, com quatro tratamentos e seis repetições. Observou-se na fase de restrição alimentar que houve um decréscimo linear para as concentrações bioquímicas de ureia, glicose, GGT e fósforo; contrariamente, a concentração de colesterol aumentou linearmente ao final do período restritivo. A restrição alimentar influenciou negativamente nas concentrações de triglicerídeos e creatinina, diferentemente, os valores de proteínas totais e albumina apresentaram aumento significativo com o período restritivo. Já na realimentação, observou-se comportamento linear decrescente para ureia, glicose, GGT e magnésio. No segundo ensaio, verificou-se que as concentrações de proteínas totais, globulina e creatinina apresentaram diferença $(\mathrm{P}<0,05)$ entre os períodos de coleta. Os níveis de restrição alimentar afetaram o metabolismo proteico e interferiram também no metabolismo energético e mineral e a realimentação resultou em alteração no metabolismo proteico e energético.

Palavras-chave: bioquímica clínica; jejum; nutrição; ovinos.

\begin{abstract}
The objective of this study was to evaluate the metabolic profile of 24 male Santa Ines sheep, with initial mean live weight of $20 \pm 1.25 \mathrm{~kg}$, submitted to feed restriction followed by refeeding, distributed into four treatments with $0,20,40$ or $60 \%$ of food restriction. Two trials were carried out, one concerning restriction and the other one for feedback. For this, a completely randomized experimental design was used, with four treatments and six replicates. It was observed in the food
\end{abstract}


restriction phase that there was a linear decrease in biochemical concentrations of urea, glucose, GGT, and phosphorus; conversely, the cholesterol concentration increased linearly at the end of the restrictive period. Food restriction had a negative effect on triglyceride and creatinine concentrations. Differently, total protein and albumin values increased significantly with the restriction period. In the refeeding, a linear decreasing behavior was observed for urea, glucose, GGT and magnesium. In the second assay, total protein, globulin and creatinine concentrations were found to differ $(\mathrm{P}<0.05)$ between the collection periods. Food restriction levels affected protein metabolism and also interfered with energy and mineral metabolism, and refeeding resulted in altered protein and energy metabolism. Keywords: clinical biochemistry; fasting; nutrition; sheep.

Recebido em: 30 de julho de 2014.

Aceito em: 19 de junho de 2018.

\section{Introdução}

Em virtude da diversidade de climas e raças ovinas criadas no Brasil, distintos sistemas de produção podem ser utilizados. Dentre os fatores imprescindíveis para a escolha do sistema está a alimentação, já que ela tem influência direta sobre o custo de produção animal.

Manejos alimentares que alternam períodos de restrição energética com períodos de atendimento das exigências nutricionais podem ser utilizados com o objetivo de auxiliar a promover o crescimento compensatório nos animais ${ }^{(1)}$. Entretanto, o desenvolvimento de estratégias eficientes para maximizar o retorno econômico da atividade exige um aprofundamento no conhecimento do perfil metabólico dos animais submetidos a diferentes níveis de disponibilidade de $\operatorname{alimentos}^{(2)}$.

Para obter sucesso na melhoria dos plantéis e no retorno econômico da atividade, o uso do Perfil Metabólico (PM) é uma alternativa interessante, sendo evidenciado por muitos pesquisadores que a utilizam para fins econômicos, avaliação de dietas e ampliação científica do exame ${ }^{(3,4)}$.

Com a formulação de dietas que visam o crescimento compensatório, reações adversas e irreversíveis ao desenvolvimento do animal são mínimas ou inexistentes. Após longa restrição alimentar, o crescimento compensatório passa a ter ação na base metabólica ou endócrina, além disso, afeta o crescimento e o ganho de peso dos animais por meio da diminuição na concentração de metabólitos e aumento na concentração de hormônio de crescimento ${ }^{(5-7)}$.

O PM possui três variáveis (status) que representam as principais vias metabólicas no animal: energético, mineral e proteico. Para representação do status energético do animal ou do rebanho, usam-se principalmente dosagens de glicose, beta-hidroxibutirato, colesterol e ácidos graxos livres. O cálcio, o magnésio, o sódio, o fósforo inorgânico e o potássio representam os macrominerais e são os mais utilizados como indicadores do status mineral. Já na determinação do status proteico dos animais, são utilizadas as dosagens sanguíneas de hemoglobina, proteínas totais, globulinas, albumina e também a ureia ${ }^{(8)}$. Segundo Vieira et al. ${ }^{(9)}$, pode-se ainda complementar os testes de PM com dosagem de enzimas específicas como gama-glutamiltransferase (GGT).

Nesse sentido, a submissão de animais a restrição alimentar pode ter influência sobre o perfil bioquímico e, consequentemente, no metabolismo dos ovinos, porém, os dados encontrados na 
literatura são escassos para essa prática e mais estudos são necessários para compreender os efeitos da restrição alimentar seguida de ganho compensatório sobre o metabolismo de cordeiros. Dessa forma, objetivou-se com este trabalho avaliar o efeito do crescimento compensatório após o período de restrição alimentar sobre o perfil metabólico de cordeiros terminados em confinamento.

\section{Material e Métodos}

O experimento foi conduzido no Setor de Ovinocultura da Fazenda Experimental Prof. Dr. Antonio Carlos dos Santos Pessoa, localizado na Linha Guará, pertencente ao Núcleo de Estações Experimentais da Universidade Estadual do Oeste do Paraná, Campus de Marechal Cândido Rondon - PR. Todos os procedimentos deste estudo foram aprovados pelo Comitê de Ética e Pesquisa da Universidade Federal do Oeste do Paraná - Unioeste, sob número de protocolo 01512.

Foram utilizados 24 cordeiros da raça Santa Inês, machos não castrados, nascidos durante o mês de fevereiro de 2013 e desmamados aos 60 dias de idade, distribuídos em delineamento experimental inteiramente casualizado com quatro tratamentos que compreenderam $0,20,40$ ou $60 \%$ de restrição alimentar quantitativa e posterior alimentação a vontade por igual período de tempo.

Ao atingirem $20 \mathrm{~kg}$ de peso vivo $( \pm 1,25 \mathrm{~kg})$ e aproximadamente 73 dias de idade ( \pm 11 dias), os animais foram submetidos a sete dias de adaptação à dieta e às instalações providas de baias individuais de 2,0 $\mathrm{m}^{2}$ com piso suspenso ripado, com bebedouros e comedouros. Nesse período, considerado como fase pré-experimental, a ingestão de alimentos foi calculada de forma que os animais pudessem desfrutar de consumo voluntário com $10 \%$ de sobras.

A dieta experimental no tratamento sem restrição alimentar foi constituída de $40 \%$ de volumoso e $60 \%$ de concentrado, sendo formulada para atender às exigências para ganho de peso de $200 \mathrm{~g} / \mathrm{dia}$ segundo Oliveira et al. ${ }^{(10)}$. Os alimentos foram fornecidos às $8 \mathrm{~h}$ e às $17 \mathrm{~h}$, na forma de dieta completa na base de feno de Capim-tifton 85 triturado em partículas de 3 a $5 \mathrm{~cm}$, milho moído, farelo de soja e mistura mineral (Tabela 1).

Tabela 1. Composição centesimal dos alimentos e bromatológica da dieta experimental

\begin{tabular}{|c|c|}
\hline Alimentos & Quantidades (\%) \\
\hline Feno de Tifton 85 & 40,00 \\
\hline Farelo de Soja & 23,40 \\
\hline Milho & 36,00 \\
\hline Sal Mineral ${ }^{1}$ & 0,60 \\
\hline Total & 100,00 \\
\hline \multicolumn{2}{|c|}{ Composição bromatológica (\%) } \\
\hline Matéria seca & 96,28 \\
\hline Matéria mineral & 5,57 \\
\hline Fibra em detergente neutro & 32,49 \\
\hline Proteina bruta & 18,06 \\
\hline Nutrientes digestiveis totais & 77,35 \\
\hline
\end{tabular}


O experimento foi dividido em dois períodos, cada um com 64 dias de duração. No primeiro período, os animais foram distribuídos aleatoriamente em quatro níveis de restrição alimentar, 0, 20, 40 e 60\%. $\mathrm{O}$ fornecimento da dieta para os animais em restrição alimentar foi determinado com base no consumo de matéria seca (MS) efetuado pelos animais com alimentação à vontade ( $0 \%$ de restrição), ou seja, $80 \%, 60 \%$ e 40\% do consumo dos animais com alimentação ad libitum. Já no segundo período, chamado de período de realimentação, a dieta foi fornecida à vontade para todos os animais, independente da restrição anteriormente imposta.

As coletas sanguíneas foram realizadas às $8 \mathrm{~h}$ com os animais em jejum, e as coletas foram feitas em três etapas do experimento: ao início da restrição, ao final da restrição e ao final da realimentação. Foram coletados $8 \mathrm{~mL}$ de sangue de cada animal através da venopunção da jugular com utilização de agulha 40X12. Uma fração do sangue $(4 \mathrm{~mL})$ foi inserida em sistema de tubos com vácuo (vacutainer $\left.{ }^{\circledR}\right)$ com EDTA e outra fração $(4 \mathrm{~mL})$ em tubos com vácuo sem anticoagulante, respeitando essa ordem pelo risco de formação de coágulo no caso de tubos com EDTA em relação aos sem anticoagulante. As amostras foram acondicionadas em caixas isotérmicas com gelo até a chegada ao laboratório.

As amostras foram processadas nos laboratórios do CMETL-Oeste do Curso de Zootecnia da UNIOESTE. O hemograma foi realizado a partir da amostra de sangue total com EDTA dentro de 24 horas após a coleta, com o auxílio do equipamento multiparamétrico do tipo PocH-100i $\mathrm{V}$, que determinou a higidez dos animais pela determinação do número total de hemácias, hemoglobina, hematócrito e leucograma.

As amostras de soro e plasma, obtidas por centrifugação por 15 minutos a $3500 \mathrm{rpm}$, foram acondicionadas em microtubos do tipo eppendorf identificadas e congeladas em temperatura inferior a $-20^{\circ} \mathrm{C}$ até o momento da análise.

As análises bioquímicas foram realizadas após o descongelamento das amostras com soro e plasma em temperatura ambiente por aproximadamente uma hora ou até que a amostra estivesse completamente descongelada. Posteriormente, foi realizada uma pré-agitação dos microtubos para evitar compactação no fundo dos recipientes dos componentes a serem avaliados. Todos os metabólitos analisados foram determinados em triplicada por meio de espectrofotometria.

A quantificação dos metabólitos proteicos: proteínas totais, albumina e ureia foram realizadas de acordo com métodos colorimétricos através de kits comerciais (Labtest ${ }^{\circledR}$ Diagnóstica SA, Belo Horizonte, Brasil), por meio de técnicas de fotocolorimetria com o auxílio de um analisador Bioquímico Semiautomático Spectrum ${ }^{\circledR}$ - Celer. A globulina foi determinada por equação (Valor da amostra de proteínas totais subtraindo-se o valor da amostra de Albumina). A proteína total foi determinada pelo método de Biureto, a albumina pelo reagente de Verde de Bromocresol e a ureia pelo método de Berthelot.

O perfil energético, compreendido pelos metabólitos glicose, triglicerídeos e colesterol foi determinado pelo método enzimático de ponto final (Labtest Diagnóstica SA, Brasil), pelo método descrito por Barham \& Trinder $^{(11)}$ (Labtest Diagnóstica SA, Brasil) e pelo método enzimático colorimétrico de ponto final (Labtest Diagnóstica SA, Brasil), respectivamente.

Já o cálcio sérico foi determinado pelo método púrpura de ftaleína (Labtest Diagnóstica SA, Brasil); o fósforo inorgânico sérico pelo método de molibdato de amônio (Labtest Diagnóstica SA, Brasil); e 
o magnésio sérico pelo método de magon sulfonado (Labtest Diagnóstica SA, Brasil). Com base nas concentrações séricas de albumina e globulina, do cálcio e do fósforo, foram obtidas as relações albumina:globulina e cálcio:fósforo, respectivamente.

Complementando o perfil metabólico dos animais avaliados no ensaio, foram determinados os níveis séricos de Creatinina e Gama glutamil transferase (GGT), pelo método cinético de dois pontos (Labtest Diagnóstica SA, Brasil) e pelo método cinético de Szasz Modificado (Bioclin), respectivamente.

Os dados foram submetidos ao teste $\mathrm{F}$ de análise de variância, quando detectadas diferenças significativas, a análise de regressão foi utilizada para estudo dos níveis de restrição alimentar, e teste Tukey para comparação entre coletas. $\mathrm{Na}$ ausência de efeito de tratamento foram calculadas médias referentes aos tratamentos 20, 40 e 60\% de restrição nos três períodos de coleta estudados. Todos os procedimentos estatísticos foram avaliados a $5 \%$ de probabilidade, pelo programa estatístico SISVAR ${ }^{\circledR}$.

\section{Resultados e Discussão}

Observou-se que, no início do período de restrição alimentar, as concentrações de proteínas totais, albumina, globulinas, relação albumina/globulinas, ureia, colesterol, triglicerídeos, glicose, GGT, creatinina, cálcio, fósforo, relação $\mathrm{Ca} / \mathrm{P}$ e magnésio (Tabela 2) mantiveram-se de acordo com os padrões fisiológicos para a espécie ${ }^{(12,13)}$.

Tabela 2. Concentrações sanguineas de proteinas totais, albumina, globulina, relação albumina/globulina (Alb:Glo), ureia, colesterol total, triglicerideos, glicose, GGT, creatinina, fósforo e relação cálcio:fósforo e magnésio de cordeiros Santa Inês ao início do periodo experimental

\begin{tabular}{lc}
\hline \multicolumn{1}{c}{ Variáveis } & Concentrações sanguíneas médias \\
\hline Proteínas totais (g/dL) & 5,89 \\
Albumina (g/dL) & 2,92 \\
Globulinas (g/dL) & 2,97 \\
Relação Alb:Glo & 1,04 \\
Ureia (mg/dL) & 25,74 \\
Colesterol (mg/dL) & 55,01 \\
Triglicerídeos (mg/dL) & 20,11 \\
Glicose (mg/dL) & 78,32 \\
GGT (UI/L) & 43,66 \\
Creatinina (mg/dL) & 1,41 \\
Cálcio (mg/dL) & 12,14 \\
Fósforo (mg/dL) & 7,39 \\
Relação Ca:P & 1,64 \\
Magnésio (mg/dL) & 2,46 \\
\hline
\end{tabular}

Porém as proteínas totais tiveram níveis inferiores quando comparadas com a literatura $(6,0$ a 7,9 $\mathrm{g} / \mathrm{dL})^{(12)}$, este aspecto pode ser justificado pela menor eficiência metabólica na utilização das 
proteínas em animais jovens quando comparados a animais adultos e pela redução linear nas exigências para a mantença de ovinos em crescimento pelo decréscimo na taxa de renovação proteica no organismo ${ }^{(2)}$.

Com relação ao perfil energético, de acordo com Kozloski et al. ${ }^{(14)}$, os ruminantes possuem rotas metabólicas gliconeogênicas hepáticas alternativas para manutenção dos níveis glicêmicos na circulação no período pós-prandial e jejum. Além disso, a alta demanda de glicose para o crescimento animal pode tornar os níveis deste marcador bioquímico constante e sua oscilação pode estar relacionada ao estresse adaptativo ${ }^{(15)}$.

Ao final da restrição alimentar, as concentrações de proteínas totais, albumina, globulinas, relação albumina/globulinas, triglicerídeos, creatinina, cálcio e magnésio não diferiram significativamente nos níveis de restrição alimentar estudados (Tabela 3). Sendo o estado nutricional de um indivíduo resultante do equilíbrio entre os aportes nutricionais e gastos de energia e proteína, pode-se inferir que o período de restrição ao qual os animais foram expostos não foi suficientemente prolongado para proporcionar alterações nestes metabólitos. Peixoto et al. ${ }^{(3)}$ relatam que, em virtude da baixa velocidade da síntese e de degradação das proteínas pelos ruminantes, é necessário um longo período de exposição a restrição alimentar para se detectar mudanças significativas nos indicadores proteicos e energéticos.

Da mesma forma, $\operatorname{Bezerra}^{(16)}$ descreve que, quando há desequilíbrios curtos e brandos na dieta, o metabolismo sofre ajustes, utilizando as reservas corporais, de forma a não alterar o perfil bioquímico sérico dos animais. Em contrapartida, Ryan ${ }^{(17)}$ relata que períodos longos, ou até mesmo restrições severas, esgotam substancialmente as reservas corporais, fazendo com que a compensação metabólica seja ineficiente ou nula.

Tabela 3. Concentrações sanguineas de proteinas totais, albumina, globulina, relação albumina/globulina (Alb:Glo), ureia, colesterol total, triglicerídeos, glicose, GGT, creatinina, cálcio, fỏsforo e relação cálcio:fósforo e magnésio de cordeiros Santa Inês ao final da restrição alimentar

\begin{tabular}{|c|c|c|c|c|c|c|c|}
\hline \multirow[b]{2}{*}{ Variáveis } & \multicolumn{4}{|c|}{ Niveis de restrição } & \multirow[b]{2}{*}{ Equação } & \multirow[b]{2}{*}{$\mathbf{R}^{2}$} & \multirow[b]{2}{*}{$\begin{array}{l}\text { CV } \\
(\%)\end{array}$} \\
\hline & $0 \%$ & $20 \%$ & $40 \%$ & $60 \%$ & & & \\
\hline Proteinas totais (g/dL) & 6,39 & 6,81 & 6,42 & 7,01 & NS & - & 9,20 \\
\hline Albumina $(\mathrm{g} / \mathrm{dL})$ & 3,39 & 3,70 & 3,34 & 3,75 & NS & - & 16,56 \\
\hline Globulinas (g/dL) & 2,99 & 3,10 & 3,07 & 3,26 & NS & - & 16,86 \\
\hline Relação Alb:Glo & 1,16 & 1,26 & 1,11 & 1,17 & NS & - & 28,79 \\
\hline Ureia (mg/dL) & 42,15 & 35,12 & 32,85 & 26,65 & $41,50-0,243 x$ & 96,84 & 15,01 \\
\hline Colesterol (mg/dL) & 54,94 & 58,59 & 59,91 & 62,51 & $55,87+0,120 \mathrm{x}$ & 96,87 & 5,46 \\
\hline Triglicerídeos $(\mathrm{mg} / \mathrm{dL})$ & 14,12 & 15,28 & 15,34 & 17,32 & NS & - & 17,46 \\
\hline Glicose (mg/dL) & 80,91 & 74,96 & 70,25 & 67,14 & $80,227-0,230 \mathrm{x}$ & 98,12 & 7,26 \\
\hline GGT $(\mathrm{UI} / \mathrm{L})$ & 53,01 & 48,58 & 44,42 & 42,78 & $52,457-0,172 x$ & 97,32 & 2,83 \\
\hline Creatinina (mg/dL) & 1,20 & 1,19 & 1,24 & 1,27 & NS & - & 7,23 \\
\hline Cálcio (mg/dL) & 9,27 & 9,68 & 8,78 & 11,88 & NS & - & 24,35 \\
\hline Fósforo (mg/dL) & 6,91 & 6,88 & 6,70 & 5,83 & $7,101-0,017 x$ & 75,38 & 9,72 \\
\hline Relação Ca:P & 1,38 & 1,43 & 1,27 & 2,02 & $\begin{array}{c}1,399-0,014 x+ \\
0,00035 x^{2}\end{array}$ & 84,44 & 25,82 \\
\hline Magnésio (mg/dL) & 2,45 & 2,18 & 2,43 & 2,29 & NS & - & 19,28 \\
\hline
\end{tabular}


Identificou-se, no final do período de restrição alimentar, queda significativa nos níveis de ureia e glicose, de forma linear com o aumento no nível da restrição alimentar imposto. Entretanto, a concentração de ureia corrobora com o proposto na literatura para ovinos, o qual deve estar entre 24 a $50 \mathrm{mg} \mathrm{dL}^{-1(17)}$. Por outro lado, o nível de glicose nos animais que não passaram pela restrição ficou levemente acima do intervalo considerado ideal por Kaneko, que é de 50-80 mg dL-1(12).

Wittwer et al. ${ }^{(18)}$ e Menezes et al. ${ }^{(19)}$ mencionam que, em ruminantes, a diminuição dos níveis de ureia sanguínea pode estar relacionada à deficiência de compostos nitrogenados na dieta, situação evidenciada no estudo. Isso porque, quando o aporte proteico dietético é baixo, ocorre decréscimo na concentração de amônia no rúmen, com uma consequente diminuição nos teores de ureia nos líquidos corpóreos $^{(20)}$.

Apesar da diminuição nos níveis de glicemia com o aumento da restrição alimentar, o organismo dos animais em jejum procurou se ajustar à homeostase energética de forma indireta, obtendo energia para a sua manutenção através da proteólise e da lipólise. Para González et al. ${ }^{\left({ }^{8}\right)}$, os níveis de glicose têm poucas variações em decorrência de controles homeostáticos presentes no animal ruminante, principalmente envolvendo a regulação hormonal da insulina e glucagon, e dos glicocorticoides sobre o glicogênio e a gliconeogênese, respectivamente. Bezerra et al. ${ }^{(16)}$ avaliaram o perfil metabólico em novilhas Sindi submetidas à restrição de $0 \%, 20 \%$ e $40 \%$ e observaram comportamento decrescente semelhante ao estudado neste experimento para o teor de glicose durante a restrição alimentar.

Ocorreram reduções significativas nas concentrações de GGT com o aumento dos níveis de restrição alimentar, no entanto, os valores permaneceram dentro do preconizado pela literatura ${ }^{(12)}$, o que pode ser explicado pelo aumento de síntese proteica em decorrência do desenvolvimento corporal dos cordeiros. Vieira et al. ${ }^{(9)}$ determinaram padrões de referência para concentrações séricas de GGT e verificaram a influência do fator etário sobre os níveis essa enzima. A GGT também é utilizada para o monitoramento de injúrias hepáticas, dessa forma sugere-se que a restrição alimentar não causou toxicidade hepática.

Durante a restrição alimentar, houve decréscimo linear para o Fósforo, fato que pode ser explicado por se tratar de animais jovens com alta eficiência na absorção desse mineral e, consequentemente, alta taxa de mobilização e crescimento ósseo. De acordo com Kaneko et al. ${ }^{(12)}$, os valores médios de Fósforo para espécie ovina se encontram entre 5,0 e 7,3 mg/dL, e os valores encontrados neste período se comportaram semelhantes às concentrações obtidas no início do experimento. O efeito quadrático da relação cálcio/fósforo pode ser justificado pelo decréscimo no início da restrição alimentar, contudo não diverge do proposto por Riet-Correa ${ }^{(21)}$.

Ainda que alguns metabólitos apresentaram decréscimo de suas concentrações, como no caso do fósforo, glicose e ureia, o colesterol teve uma elevação considerável com o aumento da restrição imposta no final do primeiro ensaio. De acordo com Ingraham \& Kapiel $^{(22)}$, este comportamento ocorre pela mobilização de gorduras de reserva.

Para Ryan ${ }^{(17)}$, o estresse nutricional, decorrente da limitação de nutrientes fornecidos pelos alimentos, impede o animal de expressar seu potencial de crescimento e tem consequências diretas no seu desempenho. Fenômeno que pode ser explicado pelas baixas concentrações dos metabólitos proteicos e energéticos, o que resulta em baixa síntese proteica e deposição muscular.

Verifica-se, na Tabela 4, que os animais no início da restrição alimentar e no final da restrição 
apresentam valores estatisticamente semelhantes para as concentrações bioquímicas de globulinas, relação albumina/globulina e cálcio. Observa-se que os valores de proteínas totais e albumina foram superiores no final da restrição, no entanto os níveis de triglicerídeos e creatinina foram superiores no início da restrição.

Foi observado, ao final da restrição alimentar, aumento das concentrações de proteínas totais e albumina, entretanto dentro das margens de referência ${ }^{(12)}$. Esse aumento da concentração sanguínea de proteínas totais e albumina no final da fase de restrição alimentar já era esperado em virtude da função de reserva metabólica proteica da albumina, em que o organismo do animal pode recorrer para manutenção e regulação das funções orgânicas, como transporte de moléculas e hormônios ${ }^{(14)}$.

Tabela 4. Concentrações médias de proteinas totais, albumina, globulinas, relação albumina/globulina (Alb/Glo), triglicerideos, creatinina, e cálcio de cordeiros Santa Inês no inicio e final do periodo de restrição alimentar

\begin{tabular}{lccr}
\hline \multirow{2}{*}{ Variáveis } & \multicolumn{2}{c}{ Periodos de restrição } & \\
\cline { 2 - 3 } & $\begin{array}{c}\text { Início da restrição } \\
\text { alimentar }\end{array}$ & $\begin{array}{c}\text { Final da restrição } \\
\text { alimentar }\end{array}$ & CV(\%) \\
\hline Proteinas totais (g/dL) & $5,88 \mathrm{~B}$ & $6,75 \mathrm{~A}$ & 8,87 \\
Albumina $(\mathrm{g} / \mathrm{dL})$ & $2,93 \mathrm{~B}$ & $3,60 \mathrm{~A}$ & 16,14 \\
Globulinas $(\mathrm{g} / \mathrm{dL})$ & 2,95 & 3,14 & 17,62 \\
Relação $\mathrm{Alb} / \mathrm{Glo}$ & 1,04 & 1,18 & 28,50 \\
Triglicerideos $(\mathrm{mg} / \mathrm{dL})$ & $21,13 \mathrm{~A}$ & $15,98 \mathrm{~B}$ & 16,71 \\
Creatinina $(\mathrm{mg} / \mathrm{dL})$ & $1,41 \mathrm{~A}$ & $1,23 \mathrm{~B}$ & 8,02 \\
Cálcio $(\mathrm{mg} / \mathrm{dL})$ & 11,38 & 10,11 & 20,30 \\
\hline
\end{tabular}

Letras diferentes na mesma linha diferem entre si a $5 \%$ de probabilidade pelo teste de Tukey. CV $(\%)=$ coeficiente de variação

O comportamento bioquímico dos triglicerídeos obtidos nesse experimento acompanhou os resultados obtidos por Costa et al. ${ }^{(15)}$. Os valores encontrados para os triglicerídeos plasmáticos nos cordeiros foram inferiores na fase final da restrição alimentar, o que pode ser explicado pela baixa mobilização de reservas de gordura em decorrência do jejum prolongado sofrido pelos animais nesta fase.

Ao final da restrição alimentar, foi detectado um decréscimo nas concentrações de creatinina. Kaneko et al. ${ }^{(12)}$ relatam que os níveis de creatinina devem se apresentar entre 1,2 a $1,9 \mathrm{mg} / \mathrm{dL}$, fato que não diverge dos encontrados tanto no início quanto no final da restrição alimentar. Segundo Vagnoni et al. ${ }^{(23)}$, a creatinina é um produto do metabolismo da creatina muscular e é eliminada do organismo em proporções constantes independentemente do nível de consumo do alimento. González et al. ${ }^{(8)}$ relatam que, apesar de a creatinina não ser afetada intimamente pelo catabolismo das proteínas tissulares e da dieta, os valores podem diminuir em situações nas quais o organismo precise mobilizar reservas endógenas.

Verificou-se, durante o período de realimentação (Tabela 5), comportamento linear decrescente para as concentrações de ureia, glicose, GGT e magnésio, no entanto não houve efeito significativo para as concentrações de proteínas totais, albumina, globulina, relação albumina/globulina, colesterol, triglicerídeos, creatinina, cálcio, fósforo e relação cálcio/fósforo. 
Tabela 5. Concentrações sanguineas de proteínas totais, albumina, globulina, relação albumina/globulina (Alb:Glo), ureia, colesterol total, triglicerídeos, glicose, GGT, creatinina, cálcio, fösforo, relação cálcio:fösforo e magnésio de cordeiros Santa Inês submetidos à realimentação após periodo restritivo de alimentos

\begin{tabular}{|c|c|c|c|c|c|c|c|}
\hline \multirow[b]{2}{*}{ Variáveis } & \multicolumn{4}{|c|}{ Restrição prévia } & \multirow[b]{2}{*}{ Equação } & \multirow[b]{2}{*}{$\mathbf{R}^{2}$} & \multirow[b]{2}{*}{ CV $(\%)$} \\
\hline & $0 \%$ & $20 \%$ & $40 \%$ & $60 \%$ & & & \\
\hline Proteinas totais (g/dL) & 5,87 & 5,46 & 5,49 & 5,93 & NS & - & 8,43 \\
\hline Albumina $(\mathrm{g} / \mathrm{dL})$ & 3,17 & 3,21 & 3,13 & 3,10 & NS & - & 14,82 \\
\hline Globulinas (g/dL) & 2,70 & 2,24 & 2,35 & 2,83 & NS & - & 20,20 \\
\hline Relação Alb:Glo & 1,19 & 1,72 & 1,38 & 1,10 & NS & - & 41,09 \\
\hline Ureia (mg/dL) & 42,50 & 35,47 & 33,17 & 27,00 & $41,858-0,243 x$ & 96,84 & 14,86 \\
\hline Colesterol (mg/dL) & 48,23 & 48,97 & 49,72 & 46,09 & NS & - & 7,87 \\
\hline Triglicerideos (mg/dL) & 14,42 & 15,58 & 15,64 & 17,62 & NS & - & 17,13 \\
\hline Glicose (mg/dL) & 85,84 & 82,34 & 77,28 & 76,44 & $85,47-0,166 \mathrm{x}$ & 94,16 & 3,26 \\
\hline GGT (UI/L) & 53,21 & 48,78 & 44,91 & 42,98 & $52,657-0,172 \mathrm{x}$ & 97,32 & 2,82 \\
\hline Creatinina (mg/dL) & 1,50 & 1,49 & 1,54 & 1,57 & NS & - & 5,81 \\
\hline Cảlcio (mg/dL) & 9,44 & 8,34 & 8,80 & 9,21 & NS & - & 20,20 \\
\hline Fósforo (mg/dL) & 8,81 & 8,75 & 9,38 & 8,88 & NS & - & 22,36 \\
\hline Relação Ca:P & 1,07 & 0,98 & 1,04 & 1,16 & NS & - & 33,78 \\
\hline Magnésio (mg/dL) & 3,02 & 2,70 & 2,43 & 2,35 & $2,969-0,011 x$ & 94,52 & 15,20 \\
\hline
\end{tabular}

Assim como o ocorrido no início e no final da restrição alimentar, houve efeito significativo para GGT, sendo que os valores se apresentaram dentro dos limites de normalidade ${ }^{(12)}$. Esse efeito já era esperado principalmente pela adaptação metabólica dos animais à dieta e também aos níveis de alimentação impostos $^{(24)}$.

$\mathrm{Na}$ realimentação, foram observadas diferenças estatísticas no comportamento das concentrações de glicose, ureia e magnésio, conforme a restrição imposta previamente. Assim que submetidos à realimentação, os animais recuperaram seus valores de glicose e ureia, de forma linear, entretanto, não obtiveram valores similares quando comparados entre os níveis restritivos. Hoch et al. ${ }^{(25)}$ e Bezerra ${ }^{(16)}$ também detectaram recuperação na concentração de ureia e glicose do plasma durante o período de realimentação.

O manejo restritivo prévio foi possivelmente responsável pela redução linear nos valores encontrados para o marcador mineral magnésio na fase de realimentação. Goff ${ }^{(26)}$ relata que não há controle intrínseco e rigoroso do magnésio no organismo animal, sendo assim, sua concentração sérica reflete diretamente o nível nutricional da dieta. Os animais possuem marcada individualidade para crescimento e essa diferença pode se dever simplesmente ao apetite, portanto, a redução linear apresentada neste experimento pode ser indicativa de fatores intrínsecos do indivíduo, como também carência ou não aproveitamento desse mineral na dieta.

Os valores encontrados para os Triglicerídeos durante a realimentação não divergiram dos padrões fisiológicos $(9-30 \mathrm{mg} / \mathrm{dL})$ relatados por Kaneko et al. ${ }^{(12)}$. Para Bazin \& Brisson ${ }^{(27)}$, durante o crescimento 
animal ocorre um declínio na concentração plasmática lipídica, principalmente em virtude do desmame, pois a energia adquirida pela alimentação à base de leite é substituída por outra fonte energética na forma de ácidos graxos voláteis e que são absorvidos no rúmen.

Portanto, animais que se adaptam ao metabolismo proteico e energético precocemente conseguem aproveitar melhor os alimentos impostos. Todo esse processo depende diretamente da ingestão de alimentos, e é regulado de forma intrínseca via hormônios insulina, imunoglobulinas e hormônio do crescimento, fato que resulta em menor demanda energética e síntese de proteína muscular e acarreta queda do crescimento animal ${ }^{(28)}$.

Vários fatores podem influenciar o perfil metabólico e, em consequência, o ganho compensatório; entre eles, o grau de maturidade em que se encontram os animais ${ }^{(29)}$, além da severidade e duração da restrição ${ }^{(30)}$.

Observa-se, na Tabela 6, que os animais no final da restrição alimentar e no final da realimentação apresentam valores estatisticamente semelhantes para as concentrações bioquímicas de albumina, relação albumina:globulinas, triglicerídeos e cálcio. Durante a realimentação, detectou-se valores superiores quando comparados com o final da restrição para a creatinina; no entanto, as concentrações de proteínas totais e globulinas durante a restrição alimentar mostraram-se maiores do que no período de realimentação.

Tabela 6. Concentrações médias de proteinas totais, albumina, globulina, relação albumina/globulina (Alb/Glo), triglicerideos, creatinina, e cálcio de cordeiros Santa Inês submetidos à restrição alimentar prévia seguida de realimentação

\begin{tabular}{lccc}
\hline \multirow{2}{*}{ Variáxeis } & \multicolumn{2}{c}{ Periodos de coleta } & \\
\cline { 2 - 3 } & $\begin{array}{c}\text { Final da restrição } \\
\text { alimentar }\end{array}$ & $\begin{array}{c}\text { Final da } \\
\text { realimentação }\end{array}$ & CV(\%) \\
\hline Proteinas totais (g/dL) & $6,75 \mathrm{~A}$ & $5,63 \mathrm{~B}$ & 9,42 \\
Albumina (g/dL) & 3,60 & 3,15 & 16,16 \\
Globulinas (g/dL) & $3,14 \mathrm{~A}$ & $2,48 \mathrm{~B}$ & 19,42 \\
Relação Alb/Glo & 1,18 & 1,34 & 33,05 \\
Triglicerideos (mg/dL) & 15,98 & 16,28 & 16,27 \\
Creatinina (mg/dL) & $1,23 \mathrm{~B}$ & $1,53 \mathrm{~A}$ & 6,48 \\
Cálcio (mg/dL) & 10,11 & 8,92 & 25,85 \\
\hline Letras diferentes na mesma linha diferem entre si a 5\% de probabilidade pelo teste de Tukey. CV $(\%)=$ \\
coeficiente de variação
\end{tabular}

Os valores menores das proteínas totais e globulinas ao final da realimentação, como indicadores do perfil proteico, já eram esperados, uma vez que durante este período os animais receberam alimentação " $a d$ libitum". As proteínas sanguíneas são sintetizadas principalmente pelo fígado, sendo que a taxa de síntese está diretamente relacionada ao estado nutricional do animal, portanto, animais que sofreram algum tipo de manejo restritivo, com posterior realimentação, podem apresentar queda no perfil proteico em decorrência do aumento da oferta e do consumo alimentar pelos animais ${ }^{(7)}$.

$\mathrm{Na}$ Tabela 7 observa-se que as médias das concentrações sanguíneas de glicose, colesterol, ureia, GGT, fósforo, magnésio e relação Ca:P apresentaram diferenças estatísticas entre as coletas realizadas.

O comportamento bioquímico da glicose nesse experimento acompanhou os resultados obtidos por Costa et al. ${ }^{(15)}$, sendo evidenciadas diferenças estatísticas entre as coletas, nos níveis de $40 \%$ e $60 \%$ de restrição alimentar. Os menores valores para este marcador foram encontrados ao final da restrição alimentar, os 
quais tiveram efeito significativo. Bezerra ${ }^{(16)}$ afirma que, entre as possíveis mudanças provocadas pelo regime alimentar, está a redução do ácido propiônico no fígado, o que provoca mudanças na neoglicogênese pela utilização de glicerol, lactato, alguns aminoácidos e, consequentemente, diminuição na glicemia dos animais. Durante esse período, a principal fonte de energia para o organismo animal pode ser advinda de ácidos graxos não esterificados ${ }^{(32)}$.

Tabela 7. Comparação entre as coletas para as concentrações médias de glicose, colesterol, ureia, GGT, fósforo, magnésio e relação Ca:P em ovinos Santa Inês submetidos ao manejo para ganho compensatório

\begin{tabular}{|c|c|c|c|c|}
\hline \multirow[b]{2}{*}{ Coletas } & \multicolumn{4}{|c|}{ Niveis de restrição } \\
\hline & $0 \%$ & $20 \%$ & $40 \%$ & $60 \%$ \\
\hline \multicolumn{5}{|c|}{ Glicose } \\
\hline Inicio da restrição & 81,99 & 80,32 & $76,63 \mathrm{~A}$ & $74,33 \mathrm{~A}$ \\
\hline Final da restrição & 80,91 & 74,96 & $70,25 \mathrm{~B}$ & $67,14 \mathrm{~B}$ \\
\hline Final realimentação & 85,84 & 82,34 & $77,28 \mathrm{~A}$ & $76,44 \mathrm{~A}$ \\
\hline CV $(\%)$ & 5,55 & 6,87 & 2,91 & 3,41 \\
\hline \multicolumn{5}{|c|}{ Colesterol } \\
\hline Inicio da restrição & $53,84 \mathrm{~A}$ & $56,00 \mathrm{~A}$ & $53,23 \mathrm{~B}$ & $56,96 \mathrm{~A}$ \\
\hline Final da restrição & $54,94 \mathrm{~A}$ & $58,59 \mathrm{~A}$ & $59,91 \mathrm{~A}$ & $62,51 \mathrm{~A}$ \\
\hline Final realimentação & $48,23 \mathrm{~B}$ & $48,97 \mathrm{~B}$ & $49,72 \mathrm{~B}$ & $46,09 \mathrm{~B}$ \\
\hline $\mathrm{CV}(\%)$ & 4,38 & 7,73 & 7,89 & 7,15 \\
\hline \multicolumn{5}{|c|}{ Ureia } \\
\hline Inicio da restrição & $31,98 \mathrm{~B}$ & 26,21 & $24,59 \mathrm{~B}$ & $20,18 \mathrm{~B}$ \\
\hline Final da restrição & $42,15 \mathrm{~A}$ & 35,12 & $32,82 \mathrm{~A}$ & $26,65 \mathrm{~A}$ \\
\hline Final realimentação & $42,50 \mathrm{~A}$ & 35,47 & $33,17 \mathrm{~A}$ & $27,00 \mathrm{~A}$ \\
\hline $\mathrm{CV}(\%)$ & 14,29 & 20,86 & 14,00 & 14,93 \\
\hline \multicolumn{5}{|c|}{ GGT } \\
\hline Inicio da restrição & 50,99 & $44,15 B$ & 43,53 & $35,96 \mathrm{~B}$ \\
\hline Final da restrição & 53,01 & $48,58 \mathrm{~A}$ & 44,71 & $42,78 \mathrm{~A}$ \\
\hline Final realimentação & 53,21 & $48,78 \mathrm{~A}$ & 44,91 & $42,98 \mathrm{~A}$ \\
\hline $\mathrm{CV}(\%)$ & 2,89 & 2,64 & 2,63 & 4,35 \\
\hline \multicolumn{5}{|c|}{ Fösforo } \\
\hline Inicio da restrição & $8,92 \mathrm{~A}$ & $7,41 \mathrm{AB}$ & $6,86 \mathrm{AB}$ & $6,36 \mathrm{~B}$ \\
\hline Final da restrição & $6,91 \mathrm{~B}$ & $6,88 \mathrm{~B}$ & $6,70 \mathrm{~B}$ & $5,83 \mathrm{~B}$ \\
\hline Final realimentação & $8,81 \mathrm{AB}$ & $8,75 \mathrm{~A}$ & $9,38 \mathrm{~A}$ & $8,88 \mathrm{~A}$ \\
\hline $\mathrm{CV}(\%)$ & 15,57 & 13,63 & 22,95 & 22,21 \\
\hline \multicolumn{5}{|c|}{ Magnésio } \\
\hline Inicio da restrição & 2,61 & $2,71 \mathrm{~A}$ & 2,34 & 2,18 \\
\hline Final da restrição & 2,45 & $2,18 \mathrm{~B}$ & 2,43 & 2,29 \\
\hline Final realimentação & 3,02 & $2,70 \mathrm{~A}$ & 2,43 & 2,35 \\
\hline $\mathrm{CV}(\%)$ & 14,40 & 11,34 & 19,45 & 12,38 \\
\hline \multicolumn{5}{|c|}{ Relação Ca/P } \\
\hline Inicio da restrição & $1,47 \mathrm{~A}$ & $1,54 \mathrm{~A}$ & $1,83 \mathrm{~A}$ & $1,72 \mathrm{AB}$ \\
\hline Final da restrição & $1,34 \mathrm{AB}$ & $1,43 \mathrm{~A}$ & $1,31 \mathrm{AB}$ & $2,02 \mathrm{~A}$ \\
\hline Final realimentação & $1,07 \mathrm{~B}$ & $0,98 \mathrm{~B}$ & $1,04 \mathrm{~B}$ & $1,16 \mathrm{~B}$ \\
\hline $\mathrm{CV}(\%)$ & 15,86 & 21,88 & 25,71 & 31,50 \\
\hline
\end{tabular}


De acordo com Bezerra ${ }^{(16)}$, havendo redução da glicose sanguínea, os animais mobilizam ácidos graxos do tecido gorduroso durante a restrição alimentar, permitindo que o uso de proteína e energia seja poupado. No entanto, quando esse manejo for prolongado ou até mesmo muito severo, pode haver mobilização muscular para reaver energia e, com isso, o animal cessa o seu desenvolvimento. Apesar do decréscimo nos valores de glicose ao final da restrição alimentar para os animais com 40 e $60 \%$ de restrição, os cordeiros não apresentaram queda no ganho de peso, o que nos permite concluir que os níveis restritivos adotados não foram severos a ponto de afetar a homeostase dos animais.

Os níveis glicêmicos no período de realimentação aumentaram, em relação ao período de alimentação restrita, nos animais submetidos aos níveis de 40 e $60 \%$ de restrição alimentar. Se por um lado, o manejo restritivo obteve resultados negativos sobre o perfil energético, por outro, a realimentação gerou imediata recuperação do status energético. Para Goularte et al. ${ }^{(31)}$, quanto maior for a presença de concentrado na dieta, maior será a massa microbiana ruminal de produtores de propionato, elevando, consequentemente, a gliconeogênese.

O perfil energético teve diferença estatística entre as coletas para o colesterol em todos os níveis estudados neste experimento. O comportamento diminuído do colesterol ao final da realimentação se deve provavelmente ao bom aporte proteico na dieta, uma vez que houve baixa necessidade de mobilização de reservas lipídicas durante esse período. Corroborando os resultados encontrados neste estudo, Borburema et al. ${ }^{(32)}$ também encontraram diferença entre os períodos de coleta.

A concentração sanguínea de colesterol foi maior no final da restrição alimentar em todos os níveis estudados quando comparada aos valores encontrados ao final do período de realimentação. Apesar desse aumento significativo, o metabólito encontrou-se dentro dos valores descritos por Kaneko et al. ${ }^{(12)}$, ou seja, 52-76 mg/dL. Situação semelhante foi relatada por Borburema et al. ${ }^{(32)}$ que, trabalhando com ovinos Santa Inês jovens e objetivando comparar níveis de restrição alimentar, observaram comportamento similar entre as coletas. Esse aspecto pode ser justificado pela mobilização hepática dos ácidos graxos livres, os quais podem seguir duas rotas: 1 - entrar para a mitocôndria dos hepatócitos e serem oxidados ou $\mathbf{2}$ - alocar-se no citosol e serem esterificados formando triglicerídeos e lipoproteínas, que são utilizadas como fontes energéticas no organismo animal( $^{(33)}$. Em suma, pode-se afirmar que a mobilização dos ácidos graxos livres durante a restrição alimentar foi responsável pelo aumento do colesterol no final desse período e que a severidade do manejo restritivo não afetou de forma substancial os mecanismos de regulação homeostática.

Para o marcador ureia foram constatadas neste experimento diferenças estatísticas entre as coletas para os níveis 0,40 e $60 \%$ de restrição alimentar. Como a amônia de origem alimentar foi provavelmente baixa, este aumento nas concentrações metabólicas da ureia, tanto no final da restrição quanto ao final da realimentação, pode ser explicado pela mobilização de aminoácidos e proteólise para geração de energia no animal e, também, pela degradação de proteínas microbianas, o que também foi evidenciado por Rule et al. ${ }^{(34)}$.

Avaliando as coletas nos períodos restritivos iniciais e finais e na realimentação, observa-se que apenas os níveis de 20 e 60\% apresentaram diferença estatística para a enzima GGT, no entanto, todos os valores para este marcador apresentaram-se dentro dos preconizados para a espécie ${ }^{(12)}$. Este resultado sugere que a enzima contribuiu de forma indireta para a síntese proteica, a qual interferiu na manutenção das concentrações de grande parte dos marcadores proteicos. 
Em relação ao marcador fósforo, todos os níveis alimentares impostos apresentaram diferença estatística entre as coletas. As concentrações séricas do fósforo reduziram com o final do manejo restritivo em relação ao final do período de realimentação para os níveis de 20 a $60 \%$ de restrição quantitativa de alimentos. Possivelmente, a causa dessa redução pode estar relacionada à disponibilidade e ingestão de minerais na dieta devido à restrição, o que foi evidenciado também por Bezerra $^{(16)}$ e Borburema et al. ${ }^{(32)}$. Os autores afirmam ainda que a deficiência prolongada do fósforo pode acarretar um baixo desenvolvimento corporal, afetando o desempenho produtivo.

A concentração de Magnésio encontrada neste experimento sofreu interferência das coletas somente para os animais que receberam $20 \%$ de restrição na alimentação. Resultado semelhante foi encontrado por Borburema ${ }^{(32)}$ ao estudar o efeito das coletas e níveis restritivos em ovinos Santa Inês. Verifica-se também, na Tabela 7 , que os valores encontrados para a relação $\mathrm{Ca} / \mathrm{P}$ apresentaram diferenças estatísticas entre as coletas. Essa diferença já era esperada, uma vez que os animais envolvidos no experimento eram jovens em fase de crescimento, o que torna os valores de cálcio e fósforo oscilantes e, consequentemente, a relação $\mathrm{Ca} / \mathrm{P}$. González ${ }^{(8)} \mathrm{e} \mathrm{Goff}^{(31)}$ afirmam que, apesar de os ruminantes possuírem controle endócrino eficiente sobre as concentrações de cálcio, o mesmo não acontece no caso dos minerais fósforo e magnésio, que necessitam ser suplementados via alimentação e são regulados pelos níveis minerais presentes no alimento e, também, pela quantidade do mineral ingerido na dieta pelo indivíduo.

\section{Conclusão}

O manejo, visando à indução de ganho compensatório de cordeiros Santa Inês terminados em confinamento, interfere nas sínteses de metabólitos importantes para o crescimento animal, elevando os níveis séricos de percussores para síntese proteica, como a glicose e ureia.

O uso da restrição alimentar, em até $60 \%$ do consumo ad libtum, como alternativa nutricional, demonstra que os animais suportaram um período de 64 dias de restrição, sem a presença de transtornos metabólicos ou mesmo distúrbios que possam afetar a produtividade.

\section{Agradecimentos}

Ao Laboratório Labtest ${ }^{\circledR}$ Diagnóstica SA, pelo apoio e fornecimento dos kits de reagentes, fomentando a pesquisa animal.

\section{Referências}

1. Costa PB, Queiroz AC, Magalhães ALR, Zorzi K, Mello RO, Oliveira AAMA. Parâmetros digestivos e produção de proteína microbiana em novilhas em crescimento compensatório. Arq. Bras. Med. Vet. Zootec. 2008; 60(5): 1135-1141.

2. Pereira ES, Lima FWR, Marcondes MI, Rodrigues JPP, Campos ACN, Silva LP, Bezerra LR, Pereira MWF, Oliveira RL. Energy and protein requirements of Santa Ines lambs, a breed of hair sheep. Animal. 2017; 11(12): 2165-217. 
3. Peixoto LAO, Osório MTM. Perfil metabólico proteico e energético na avaliação do desempenho reprodutivo em ruminantes. Revista Brasileira de Agrociência. 2007; 13(3): 299-304.

4. Libardo MA, Alvarez JC, Garay OV. Analisis del perfil metabolico de hembras ovinas criollas gestantes en condiciones de pastoreo extensivo. Revista Científica de la Facultad de Ciencias Veterinarias. 2011; 21(4): 335-339.

5. Blum JW, Schnyder W, Kunz PL, Blom AK, Bickel H, Schürch A. Reduced and compensatory growth: Endocrine and metabolic changes during feed restriction and refeeding in steers. Journal of Nutrition. 1985; 115(4): 417-424.

6. Hayden JM, Williams JE, Collier RJ. Plasma growth hormone, insulin-like growth factor, insulin, and thyroid hormone association with body protein and fat accretion in steers undergoing compensatory gain after dietary energy restriction. Journal of Animal Science. 1993; 71: 3327-3338.

7. Hornick JL, Van Eenaeme C, Clinquart A, Diez M, Istasse L. Different periods of feed restriction before compensatory growth in Belgian Blue bulls: II. Plasma metabolites and hormones. Journal of Animal Science. 1998; 76: 260-271.

8. González FHD. O perfil metabólico no estudo de doenças da produção em vacas leiteiras. Arquivos da Faculdade de Veterinária da UFRGS. 1997; 25:13-33.

9. Vieira AC, Câmara AC, Mendonça CL, Afonso JAB. Perfil hematológico e bioquímico de ovinos suplementados com salinomicina submetidos à acidose láctica ruminal. Ciência Animal Brasileira. 2012, 13(2): 259-271.

10. Oliveira AP, Pereira ES, Pinto AP, Silva AMA, Carneiro MSS, Mizubuti IY, Ribeiro ELA, Campos ACN, Gadelha CRF. Estimativas dos requisitos nutricionais e utilização do modelo Small Ruminant Nutrition System para ovinos deslanados em condições semiáridas. Semina: Ciências Agrárias. 2014; 35(4): 1985-1998.

11. Barham D, Trinder P. An Improved colour reagent for the determination of blood glucose by the oxidase system. Analyst. 1972; 97:142-145.

12. Kaneko JJ, Harvey JW, Bruss ML. Clinical Biochemistry of Domestic Animals. 2008. 6th ed., Elsevier, London.

13. Contreras P. Indicadores do metabolismo proteico utilizado nos perfis metabólicos de rebanhos. In: González HD, Barcellos J, Patinõ HO, Ribeiro LAO. Perfil metabólico em ruminantes: seu uso em nutrição e doenças nutricionais. 2000. Porto Alegre: Gráfica da Universidade Federal do Rio Grande do Sul; 2000: 2330 .

14. Kozloski GV, Rocha JBT, Ciocca MLS. Visceral metabolism and efficiency of energy use by ruminants: review. Ciência Rural. 2001; 31(5): 909-915.

15. Costa PB, Queiroz AC, Rodrigues MT, Magalhães ALR, Zorzi K, Mello R, Silva MMC, Alves NG. Perfil metabólico e desenvolvimento da glândula mamária de novilhas leiteiras sob manejo para crescimento compensatório. R. Bras. Zootec. 2012; 41(2): 360-366.

16. Bezerra LR, Neto SG, Medeiros AN, Mariz TMA, Oliveira RL, Cândido EP, Silva AMA. Feed restriction followed by realimentation in prepubescent Zebu females. Trop Anim Health Prod. 2013; 45(5): 1161-1169.

17. Ryan WJ. Compensatory growth in cattle and sheep. Nutrition Abstracts Reviews. 1990; 60 (4): 653-664.

18. Wittwer F, Reyes JM, Opitz H, et al. Determinación de úrea en muestras de leche de rebaños bovinos para el diagnóstico de desbalance nutricional. Arch. Med. Vet. 1993; 25: 165-172.

19. Menezes DR, Araújo GGL, Oliveira RL, Bagaldo AR, Silva TM, Santos AP. Balanço de nitrogênio e medida do teor de ureia no soro e na urina como monitores metabólicos de dietas contendo resíduo de uva de 
vitivinícolas para ovinos. Revista Brasileira de Saúde e Produção Animal. 2006; 7:169-175.

20. Mouro GF, Branco AF, Macedo FAF, Guimarães KC, Alcalde CR, Ferreira RA, Prohmann PEF. Substituição do milho pela farinha de mandioca de varredura em dietas de cabras em lactação: fermentação ruminal e concentração de ureia plasmática e no leite. Revista Brasileira de Zootecnia. 2002, 31(4): 18401848.

21. Riet-Correa F. Suplementação mineral em pequenos ruminantes no semi-árido. Ciênc. Vet. Tróp. 2004; $7: 112-130$.

22. Ingraham RH, Kaplel LC. Metabolic profile testing. Vet. Clin. N. Amer.: Food Anim. Pract 1988; 4: 391411.

23. Vagnoni DB, Broderick GA, Clayton MK, Hatfield RD. Excretion of purine derivatives by Holstein cows abomasally infused with incremental amounts of purines. Journal of Dairy Science. 1997; 80(8): 1695-1702.

24. Johnson DE, Ferrell CLE, Jenkins TG. The history of energetic eficiency research: Where have we been and where are we going? Journal Animal Science. 2003; 81:E27-E38.

25. Hoch T, Begon C, Cassar-Malek I, Picard B, Savary-Auzeloux I. Mecanismes et consequences de la croissance compensatrice chez lez ruminants. INRA Productions Animales 2003; 16(1): 49-59.

26. Goff JP. Calcium and magnesium disorders. Vet Clin North Am Food Anim Pract. 2014; 30(2): 359-381.

27. Bazin RC, Brisson GJ. Plasma Lipids, ketone bodies, and glucose concentrations in calves fed high-and low-fat milk replacers. Journal of Dairy Science. 1976; 59 (7) 1301-1305.

28. Almeida TRV, Perez JRO, Chlad M, França PM, Leite RF, Nolli CP. Desempenho e tamanho de vísceras de cordeiros Santa Inês após ganho Compensatório. Rev. Bras. Zootec. 2011; 40(3): 616-621.

29. Homem Junior AC, Silva Sobrinho AG, Yamamoto SM, Pinheiro RSB, Buzzulini C, Lima CSA. Ganho compensatório em cordeiras na fase de recria: desempenho e medidas biométricas. Rev. Bras. Zootec. 2007; 36(1): 111-119.

30. Yambayamba ES, Price MA, Foxcroft GR. Hormonal status, metabolic changes, and resting metabolic rate in beef heifers undergoing compensatory growth. Journal of Animal Science. 1996; 74: 57-69.

31. Goularte SR, Ítavo LCV, Santos GT, Ítavo CCBF, Oliveira LCS, Favaro SP, Dias AM, Torres Junior RAA, Bittar CMM. Ácidos graxos voláteis no rúmen de vacas alimentadas com diferentes teores de concentrado na dieta. Arq Bras Med Vet Zootec. 2011; 63 (6): 1479-1486.

32. Borburema JB, Cezar MF, Marques DD, Cunha MGG, Pereira Filho JM, Sousa WH, Furtado DA, Costa RG. Efeito do regime alimentar sobre o perfil metabólico de ovinos Santa Inês em confinamento. Arq. Bras. Med. Vet. Zootec. 2012; 64 (4): 983-990.

33. Herdt HH. The Veterinary Clinics of North America: food animal practice. 2000; 16(2): 408.

34. Rule DC, Beitz DC, Boer G, Lyle RR, Trenkle AH, Young JW. Changes in hormone metabolite concentrations in plasma of steers during a prolonged fast. Journal of Animal Science. 1985; 61 (4): 868-875. 